\title{
IMAGENS EM BLOGS EDUCACIONAIS DE LÍNGUA INGLESA E AS POSSIBILIDADES DE SEUS USOS NA PRÁTICA PEDAGÓGICA
}
IMAGES ON EDUBLOGS DESIGNED TO TEACH ENGLISH AND THE POSSIBILITIES OF THEIR USES IN PEDAGOGICAL PRACTICES

\section{IMÁGENES EN EDUBLOGS DISEÑADAS PARA ENSEÑAR INGLÉS Y LAS POSIBILIDADES DE SUS USOS EN PRÁCTICAS PEDAGÓGICAS}

Ofélia da Conceição Machado Sagres ${ }^{1}$ Rosemary dos Santos ${ }^{2}$

\begin{abstract}
RESUMO: Este artigo é fruto da monografia final do Curso de Especialização do Programa de PósGraduação com Aplicação da Informática (EDAI) na UERJ. Tem como objetivo analisar o emprego pedagógico de imagens em ambientes virtuais. Quanto à metodologia empregada, optamos pelo estudo de caso, pois este propicia a pesquisa qualitativa de eventos autênticos e atuais. Através de uma abordagem exploratória, procurou-se analisar a natureza e o papel pedagógico das imagens empregadas em postagens de dois edublogs voltados para o ensino de língua inglesa. Para atingir tal objetivo, este estudo baseou-se em teorias a respeito de comunicação e multimodalidade e em questões como: criação digital em rede, multiletramentos, facilidade e multiplicidade de interpretações e em usos dos blogs como ambientes de aprendizagens. Assim, dialogamos com autores da semiótica e dos estudos das tecnologias digitais. Como achados da pesquisa destacamos que os recursos digitais visuais podem ser usados para trabalhar conteúdos, trocar informações e construir atividades. A junção de diferentes modos de representação sem as limitações do meio físico favorece a construção do conhecimento. Contudo, o uso dos recursos visuais nos blogs estudados ainda é subutilizado, ou seja, as imagens, na maioria dos casos, possuem apenas função estética. $\mathrm{O}$ emprego da imagem como elemento facilitador da aprendizagem e da comunicação ainda é pouco explorado no meio digital.
\end{abstract}

Submetido em: 30/04/2018 - Aceito em: 10/05/2018 - Publicado em: 26/01/2019

${ }^{1}$ Professora de língua inglesa do Colégio Pedro II e professora aposentada da Rede Municipal de Educação do Rio de Janeiro.

${ }^{2}$ Professora Adjunta do Departamento de Formação de Professores da Faculdade de Educação da Baixada Fluminense (FEBF-UERJ). Doutora e Mestre em Educação pela UERJ. Professora da Rede Municipal de Educação Duque de Caxias. Vice-coordenadora do GPDOC - Grupo de Pesquisa Docência e Cibercultura. Tutora de Educação a distância. Site: www.docenciaonline.pro.br. E-mail: rose.brisaerc@gmail.com 


\section{Revista Docência e Cibercultura}

PALAVRAS-CHAVE: blogs educacionais; imagens; semiótica.

ABSTRACT: This article is the result of the monograph written for the Specialization Course in Applied Information Technology (EDAI) at UERJ. Its aim is to go through the pedagogical use of images on virtual learning environments. In relation to the methodology, we adopted a case study approach because it allows the qualitative research on actual current events. Through an exploratory approach, this study aimed to analyze the nature and pedagogical role of images used in posts from two edublogs designed to teach English. The framework for this study was based on theories about communication and multimodality, and on issues like digital production on the Web, multiliteracies, easiness and multiplicity of interpretations and the use of blogs as learning spaces. Thus, we discuss semiotics theories and the application of digital technologies in learning. One of the major findings of this study is: visual digital resources may be used to cover syllabi, change information and build activities. The interweaving of different modes of representation without the limitations of the physical space favors knowledge construction. However, the use of visual resources in the blogs studied is still underused, i.e., these images, in most cases, just have an aesthetic function. The employment of images as facilitators of learning and communication is still poorly explored in online environments.

KEYWORDS: educational blogs; images; semiotics.

\section{INTRODUÇÃO}

Vivemos em uma sociedade chamada pós-moderna ou de informação (BELL, 1999). Nesta realidade, o conhecimento está se tornando o valor principal da economia. Revoluções tecnológicas e comunicacionais conectam pessoas e globalizam atividades. Com as novas tecnologias digitais, a interação e a participação podem ser ampliadas e a informação, no ciberespaço, torna-se líquida (BAUMAN, 2007), manipulável, hipertextual e multirreferencial.

Os novos recursos disponíveis trazem uma nova questão: a multimodalidade. A presença de imagens, cores e a preocupação com o layout já estavam presentes na mídia impressa. Contudo, como Kress (2010) destaca em sua obra, a globalização gerou alterações em termos de representação (relação entre signo e objeto). Não há mais uma predominância da modalidade escrita em relação às outras modalidades (visual e auditiva). Além disso, as imagens "parecem e funcionam de maneira diferente" das utilizadas em épocas anteriores (BEZEMER \& KRESS, 2008, p. 167). Com a evolução das tecnologias digitais, a flexibilidade, a polissemia, o hibridismo e o caráter 
representativo das imagens foram potencializados. As mudanças trazidas pelo meio digital demandam uma análise mais profunda e deixam clara a necessidade de novos letramentos.

Em nossa atuação como professores de línguas, a superposição de diferentes linguagens (verbal, visual e sonora) é considerada um facilitador de aprendizagem por muitos. Na realidade, na maior parte dos meios disponibilizados, elementos não verbais destacam-se de forma significativa. Tal fato reflete a presença do padrão visual na evolução das sociedades. Não podemos esquecer, por exemplo, que as pinturas rupestres estão entre as primeiras formas de comunicação humana. Pode-se dizer que as imagens possuem em sua natureza duas funções: a comunicacional e a pedagógica. Como Nova e Alves (2006, p. 116) destacam, as imagens:

são, em geral, percebidas muito mais rapidamente do que os textos; a memorização das imagens é, geralmente, melhor do que as das representações verbais; a maior parte dos raciocínios espontâneos utilizam a simulação de modelos mentais, frequentemente imagéticos, muito mais do que cálculos (lógicos) sobre cadeias de caracteres; as representações icônicas são independentes das línguas e por isso eliminam parte das dificuldades de tradução...Nesse sentido, o contato com o universo audioimagético constitui-se numa via privilegiada, evidentemente não a única, para a concretização do processo de construção do conhecimento.

Jewitt destaca que as perspectivas modais a respeito dos multiletramentos têm como “pressuposto básico que os sentidos são produzidos [...] através de muitas representações e recursos comunicacionais"3. A significação ocorre através de imagens, gestos, olhares, posturas corporais, som, escrita, música, fala etc. (2008, p. 246). Como professores que trabalham com comunicação e (re)construção de sentidos múltiplos, devemos lidar com diferentes modalidades e, por conseguinte, com multiletramentos. Focamos, neste estudo, em três das inúmeras práticas que se interconectam na pedagogia dos multiletramentos: o letramento linguístico (a língua inglesa), o letramento digital (novas situações de comunicação, de leitura e de autoria) e o letramento visual (capacidade de compreender a mensagem transmitida por uma imagem, contextualizá-la e analisá-la criticamente). Só a partir do conhecimento metalinguístico, os alunos poderão participar criativamente no mundo multimidiático em que vivemos.

Partindo do cruzamento de letramentos mencionado acima, foi estabelecida uma nova tríade, ou seja, este artigo trabalha com três formas de mediação. A primeira é a mediação entre a

\footnotetext{
${ }^{3}$ Todas as traduções foram feitas pelas autoras do texto.
} 


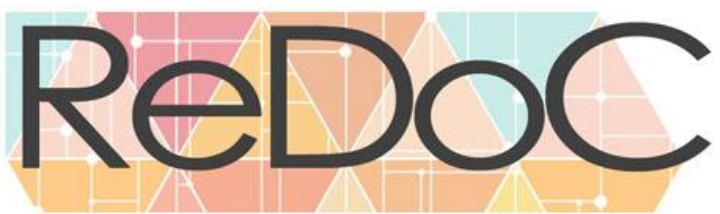

\section{Revista Docência e Cibercultura}

informação e o aluno feita pelo professor. Cabe ao educador fornecer os caminhos que podem ser trilhados (imagens selecionadas, conteúdos trabalhados...). O segundo é a mediação entre os dados e o aprendiz feita pelo digital em rede (gênero hipertextual, autonomia, multiletramentos...). O último componente da tríade é a mediação entre o significado e o aluno feita pela linguagem. Em nosso estudo, lidamos com a linguagem visual (a imagem como ponte entre os significados e os discentes para a construção dos sentidos).

$\mathrm{O}$ digital em rede possibilita adaptações e hibridismos. Imagens animadas, em movimento e estáticas agregam-se aos hipertextos, aos vídeos, às realidades virtuais e aos games. Avatares, ícones, e fotomontagens já fazem parte do cotidiano de todos que acessam a rede. Os usuários passam a atuar sobre elas, ou seja, a interagir com os elementos visuais, modificá-los e gerar sentidos distintos. A escolha das imagens fixas como objeto de pesquisa apoiou-se na vivência das autoras e na tentativa de verificar diferenças entre os meios digital e físico. Buscaram-se, então, os tipos de imagens mais comuns nos ambientes virtuais de aprendizagem selecionados para o estudo e a sua relação com o texto linguístico.

Deve-se ressaltar que vários são os olhares que oferecem classificações para os elementos visuais. Assim como as outras trilogias que serviram de base para o estudo, optou-se por uma determinada visão na interpretação. Como Bezemer et al $(2012$, p. 6) salientam, "a representação é sempre parcial" e o nosso interesse "atua como motivação para os princípios de seleção". Iremos, então, lidar com a relação das imagens com os seus objetos e com os textos linguísticos a fim de levantar hipóteses sobre a natureza dos signos visuais empregados no ensino de uma língua estrangeira.

Em uma síntese inicial, pode-se dizer que a imagem, como elemento usado para a comunicação e inserido em um contexto sociocultural, é, ao mesmo tempo, real e virtual. É real em sua relação com o objeto/referente (correspondência / referência / convenção social) e é virtual em suas polissemias. Como linguagem, a imagem é um item de mediação entre o ser humano e o mundo e também sofre a mediação da linguagem verbal e da sociedade. A vinculação dos recursos visuais com os diferentes suportes indica diferentes tramas e diferentes processos sociais. O meio digital amplia o aspecto virtual e a capacidade de mediação da imagem e possibilita a transposição de limites e o hibridismo nas categorizações. A figura abaixo representa as tríades que serviram de base para o desenvolvimento do trabalho. 
Gráfico 1 - As tríades que nortearam o estudo ${ }^{4}$.

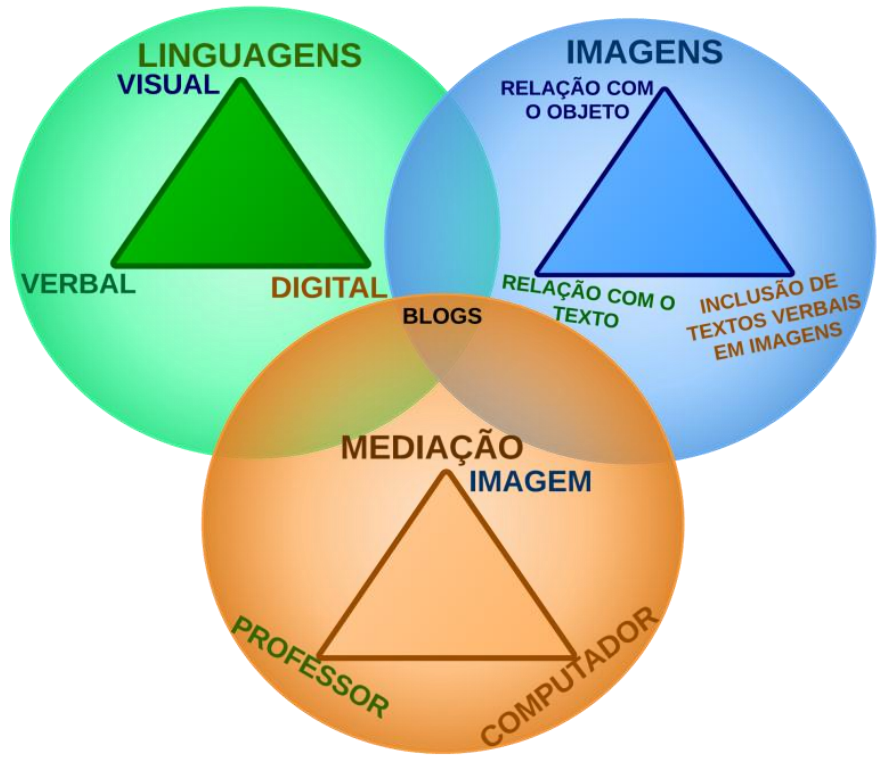

Este diagrama apresenta o blog como um dos elementos que pode permitir a junção das três tríades. Além da facilidade de criação e de manutenção, a possibilidade de agregar recursos e a natureza autoral, comunicacional e multimodal do blog, torna-o um ótimo aliado no ensino de línguas. Observa-se a capacidade que este recurso tem de possibilitar a aprendizagem colaborativa e a construção de sentidos através de processos abertos e sociais (SANTOS, 2010).

Uma vez definido o elemento de análise, era necessário estabelecer o procedimento metodológico a ser adotado. Escolheu-se o estudo de caso uma vez que este permite uma abordagem qualitativa dentro de um universo limitado para produção de dados. Além disso, este método vai ao encontro da experiência e dos interesses intrínsecos das autoras. Ao se falar em blogs e multiletramentos, lida-se com realidades atuais e, como Yin (2009) ressalta, o estudo de caso permite a investigação empírica de fenômenos contemporâneos dentro de contextos reais.

\section{MEDIAÇÕES E SENTIDOS}

\footnotetext{
${ }^{4}$ Todos os gráficos foram elaborados pelas autoras do texto.
} 


\section{Revista Docência e Cibercultura}

Uma vez que o propósito da pesquisa inclui a análise da construção de conhecimentos em língua estrangeira, faz-se necessário discutir posturas metodológicas e as noções de mediação pedagógica e de negociação. A mediação pedagógica pode ocorrer por meio do outro (professor, livro, computador...) e da linguagem (semiótica). Esta mesma noção fica clara em Vygotsky (1991) quando afirma que o desenvolvimento das funções psicológicas superiores depende da mediação dos instrumentos e dos signos. Desta forma, temos presentes os três tipos de mediações verificados na pesquisa, ou seja, a mediação docente, a mediação digital e a mediação visual (signo).

Há muito já se afirma que o papel do professor não é o de transmissor de conhecimentos. A escola é um espaço sociocultural e, como tal, deve ser dialógica, participativa, intercultural e complexa. Com as novas tecnologias comunicacionais e a quantidade de informações que circulam, cada vez mais o professor deve ser visto como um moderador que possibilita a construção dos alunos.

Embora o professor reprodutor e o professor aprendiz possam estar presentes na sala de aula e no meio digital, fica claro que a rede digital pode potencializar a práxis da coconstrução do conhecimento. No ciberespaço não há limites físicos ou temporais. Não há pontos de partida ou de chegada. Há nós que se entrelaçam em uma rede que se alastra de forma inesgotável. Os fios que formam esta rede não só armazenam conhecimento, mas também estabelecem relações comunicacionais. Silva (2006, p. 11), em sua definição a respeito do ciberespaço, destaca a natureza pedagógica do meio:

Por esse termo entenda-se o novo ambiente comunicacional que surge com a interconexão mundial de computadores e das memórias dos computadores; principal suporte de trocas e de memória da humanidade a partir do início do século XXI; novo espaço de comunicação, de sociabilidade, de organização, de informação, de conhecimento e, claro, de educação.

O uso de elementos imagéticos como mediadores culturais na construção de conhecimento, como já vimos na Introdução, data dos primórdios da sociedade. A facilidade comunicacional da imagem, provocada pela percepção de todos os seus elementos constituintes em um único momento, gera uma sintonia com aquele que a vê. Esta harmonia foi ampliada no ciberespaço. Uma vez que o hipertexto e as representações visuais caracterizam-se pela virtualização (PARENTE, 1999) e pela não linearidade, podemos afirmar que é através da interação com o usuário/leitor que os sentidos são construídos de maneira individualizada. A trajetória no meio digital e a interpretação dos recursos 


\section{Revista Docência e Cibercultura}

visuais são, então, o resultado das escolhas e vivências dos indivíduos dentro de um determinado contexto.

\section{LINGUAGENS E MULTILETRAMENTOS}

Apesar da comunicação entre os seres humanos ter começado através de imagens e gestos, muitos consideram apenas a modalidade verbal como forma de linguagem. Tal fato é reforçado pela constante associação entre linguagem escrita e conhecimento científico. A modalidade linguística ainda hoje é vista como a mais adequada para a transmissão de informações e conhecimentos por ser mais racional, eficiente, objetiva e controlada.

Defende-se neste artigo a noção que todo meio que possibilita a interação e a comunicação é uma linguagem. Assim sendo, imagens, sons, gestos, movimentos e códigos binários são considerados linguagens. Tal postura também fica clara em Santaella (1983, p. 2) ao afirmar:

Em síntese: existe uma linguagem verbal, linguagem de sons que veiculam conceitos e que se articula no aparelho fonador, sons estes que, no ocidente, receberam uma tradução visual alfabética (linguagem escrita), mas existe simultaneamente uma enorme variedade de outras linguagens que também se constituem em sistemas sociais e históricos de representação do mundo.

Como elemento de interação social, o signo é uma entidade multifacetada e polissêmica. Assim, pode-se dizer que as linguagens e a aprendizagem são processos interativos e fluidos que só ocorrem em um contexto.

Na sociedade globalizada atual, as diversas modalidades são constantemente modificadas e intercaladas a fim de atingir os objetivos comunicacionais dos falantes / usuários. Os diversos contextos culturais e semióticos e suas imbricações criam a necessidade de compreensão e controle destas diferentes formas de representação: o multiletramento (THE NEW LONDON GROUP, 1996). Assim, hipertextos e multiletramentos são, como a aprendizagem e a comunicação, dois lados da mesma moeda uma vez que se complementam. Pode-se dizer, à vista disso, que as práticas comunicativas e pedagógicas e as multimodalidades compartilham certas dimensões que aproximam suas naturezas:

a) eles são interativos; mais que isso, colaborativos;

b) eles fraturam e transgridem as relações de poder estabelecidas, em especial as relações 
de propriedade (das máquinas, das ferramentas, das ideias, dos textos [verbais ou não]); c) eles são híbridos, fronteiriços, mestiços (de linguagens, modos, mídias e culturas) (ROJO, 2012, p. 23).

Como foi possível observar, comunicação, aprendizagem e multimodalidades encontram-se unidos por características que têm as suas potencialidades ampliadas no meio digital (UNSWORTH, 2001, p.12). Com as interfaces digitais, o reconhecimento e a produção de textos em diferentes códigos podem ser facilitados e a hibridação dos mesmos de acordo com a prática social é dinamizada. O diagrama abaixo destaca as linguagens/modalidades visual, digital e verbal dentro de uma prática social de (re)construção colaborativa de sentidos e a necessidade de uma aprendizagem que abarque essa confluência de modalidades em situações comunicativas fluidas e em contextos virtuais.

Gráfico 2 - Como as noções de comunicação, aprendizagem e multiletramentos se interconectam.

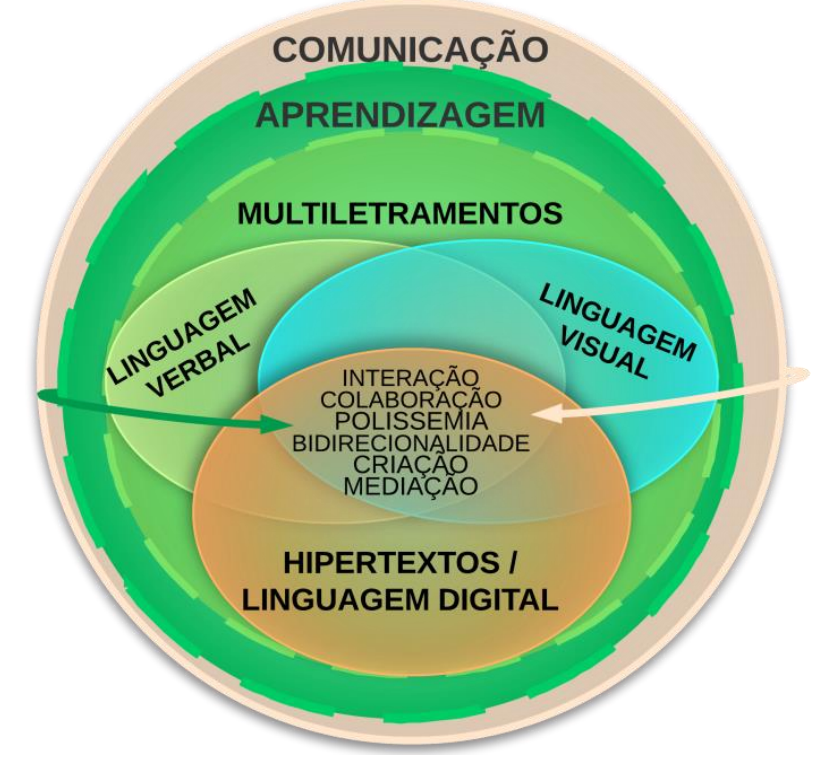

A imagem caracteriza-se por uma dualidade, isto é, ela é, ao mesmo tempo, uma representação da realidade e uma construção mental: "não há imagens como representações visuais que não tenham surgido de imagens na mente daqueles que as produziram, do mesmo modo que não há imagens mentais que não tenham alguma origem no mundo concreto dos objetos visuais" (SANTAELLA \& NÖTH, 2012, p. 15). A fim de poder dialogar com as imagens dos blogs selecionados, é necessário conhecer a natureza destas imagens, como se relacionam com o objeto que 


\section{Revista Docência e Cibercultura}

representam, com o texto escrito e com o meio no qual estão inseridas. Várias são as correntes que estudam o signo, nosso estudo, no entanto, optou por basear-se na gramática especulativa (ciência geral dos signos) de Charles Sanders Peirce e nos trabalhos da semioticista Lúcia Santaella.

As teorias por eles apresentadas fornecem os elementos para o estudo da linguagem como representação uma vez que, para estes autores, a produção de significação é um processo de mediação, contínuo, dinâmico e de sucessivas construções. Tal noção vai ao encontro da visão de comunicação, de aprendizagem e de uso do meio digital discutida nas seções anteriores. Deve-se destacar, no entanto, que não se tem a pretensão de discutir todas as nove tríades da teoria fenomenológica de Peirce. Usando os conceitos peirceanos, pode-se dizer que esta seção apresenta apenas um objeto imediato (recorte) simplificado em relação ao objeto dinâmico (semiótica peirceana).

De acordo com Peirce, a representação é mediada, ou seja, constitui-se em um sistema triádico. Este modelo semiótico baseia-se na relação entre signo-objeto-interpretante: "a ação do signo é funcionar como um mediador entre o objeto e o efeito que o signo produz em uma mente atual ou potencial" (Santaella, 2005, p. 191). Pode-se dizer, desta forma, que entramos em contato com uma determinada realidade através do representamen / signo. Os níveis semióticos obtidos fundamentam-se na natureza do signo (primeiridade / qualidade, secundidade / existente e terceiridade / lei), na natureza da relação entre signo e objeto (ícone, índice e símbolo) e na natureza entre o signo, objeto e o interpretante (PEIRCE, 1904). Escolhemos para utilizar em nossa análise de imagens a tricotomia baseada na categoria fundamental de secundidade, ou seja, aquela que analisa o caráter representativo dos signos, a sua relação com o objeto dinâmico. Para Peirce, esta é "a divisão mais importante dos signos" (CP 2.275 apud NÖTH, 2008, p. 78). Ao falar sobre esta tríade, o lógico norte-americano comenta:

[...] existem três tipos de signos que são indispensáveis para todo o raciocínio; o primeiro é o signo diagramático ou ícone, que exibe uma similaridade ou analogia com o sujeito do discurso; o segundo é o índice que, tal qual um pronome demonstrativo ou relativo, foca a atenção no objeto determinado sem descrevê-lo; o terceiro [ou símbolo] é a descrição ou nome geral que representa seu objeto através de uma associação de ideias ou da conexão habitual entre o nome e o caráter significado (CP1369, 1931).

Embora as categorias estejam sempre conectadas, é possível encontrar a dominância de uma categoria nos signos. Para Santaella e Nöth (2012, p. 148), "há imagens que são mais icônicas e 
imagens que são mais indexicais ou simbólicas". Para as autoras, o protótipo da imagem icônica (primeiridade) é a imagem abstrata. A pintura realista / forma figurativa constituem o protótipo da imagem indexical e a pintura representativa é o protótipo da imagem simbólica. Santaella (2005, p. 196) reconhece a presença da iconicidade (aspecto de similaridade) em pinturas, imagens e fotografias, no entanto reforça a noção que o caráter indicial domina a linguagem visual ao afirmar:

Com exceção das imagens despojadas do poder de referencialidade, isto é, imagens que não representam nada, que não representam qualquer forma visível que esteja fora delas, todas as imagens figurativas ou referenciais estão regidas pela dominância do índice. Embora seu poder de representação, como imagens que são, esteja ancorado numa relação de similaridade formal e, portanto, icônica, essa relação de similaridade está embutida na referencialidade, característica primordial do índice.

A classificação de uma imagem (signo visual) depende do contexto em que está inserida e dos objetivos a que se propõe, ou seja, está alicerçada na relação com os elementos que formam a sua realidade. O diagrama abaixo apresenta um resumo dos conceitos que formam a base da análise dos recursos visuais selecionados nos blogs analisados em nosso trabalho.

Gráfico 3 - O signo e suas relações

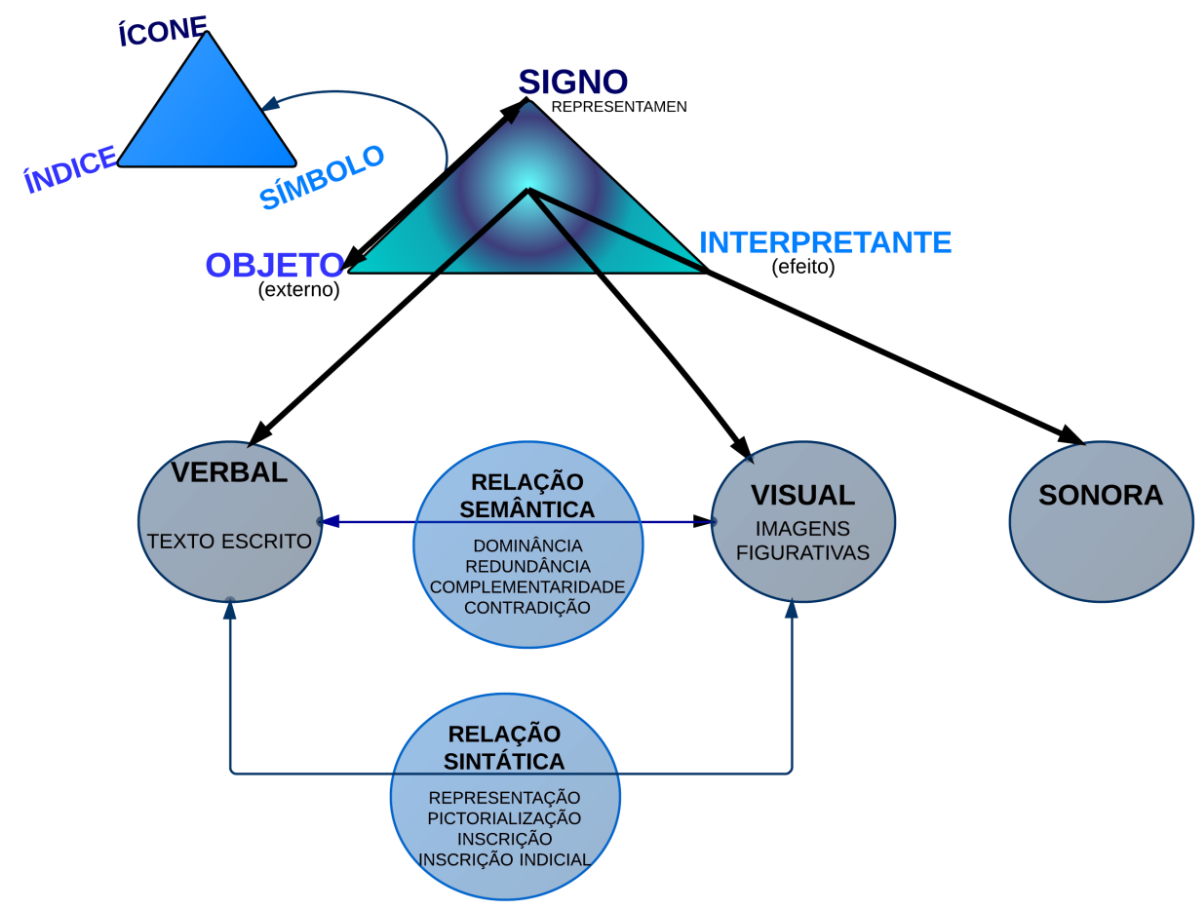

DESENHO DE UM ESTUDO 


\section{Revista Docência e Cibercultura}

Como já mencionado na introdução, pela própria questão social inerente ao objetivo da pesquisa, optou-se por uma abordagem metodológica de natureza qualitativa e exploratória. Os métodos utilizados para a obtenção de dados foram a observação participante, ou seja, uma das pesquisadoras tornou-se parte da pesquisa, e contato informal com o responsável pelo blog "Inglês na Ponta da Língua" (por e-mail).

Cabe salientar que, antes da seleção dos blogs e análise das imagens em ambientes virtuais, houve uma pesquisa (8 questões semiestruturadas) com 17 professores de línguas (7 professores de inglês, 6 professores de francês e 4 professores de português) a fím de verificar o grau de importância atribuída à imagem estática na prática pedagógica, os tipos de imagens, os suportes mais empregados e a relação dos professores com edublogs. Os dados obtidos serviram como um dos parâmetros para a análise dos signos visuais nos blogs selecionados.

Com relação à escolha dos ambientes de aprendizagem analisados, foram selecionados aqueles que as autoras já conheciam e que se caracterizavam por um grande número de consultas. Devemos destacar, no entanto, a dificuldade na obtenção de autorizações para a pesquisa. Somente o autor do blog / site "Inglês na Ponta da Língua"5 concordou em dar entrevistas e ter o seu blog estudado. Sem a autorização dos outros blogueiros, reavaliamos o projeto e optamos pela criação de um blog voltado para o ensino de língua inglesa para alunos de sexto ano do ensino fundamental ("It is a breeze" ${ }^{\prime 6}$. Uma vez que o método de pesquisa adotado caracterizou-se pela busca de integração com o objeto de estudo, a vivência da criação de um blog e das escolhas de imagens só veio enriquecer o conhecimento sobre o assunto. A fim de assegurar a legitimidade dos dados, todas as características das imagens apresentadas contaram com exemplos dos dois blogs.

A escolha das postagens para análise baseou-se em temas /conteúdos semelhantes nos dois blogs. Tal critério visou favorecer a comparação entre os recursos visuais empregados.

\section{DO PONTO AO BIT}

\footnotetext{
${ }^{5}$ https://www.inglesnapontadalingua.com.br/

${ }^{6}$ http://www.itisabreeze.blogspot.com.br/
} 


\section{Revista Docência e Cibercultura}

Uma primeira questão que merece destaque refere-se ao uso de imagens nas postagens. No blog "Inglês na Ponta da Língua", há, em geral, apenas uma imagem (não consideramos imagens presentes nos anúncios). De acordo com o autor do blog:

$\mathrm{O}$ uso de apenas uma imagem se deve a questões de carregamento da página. Aqui o assunto é mais relacionado à área de administração de um site, servidor, tempo de carregamento da página, etc. Quanto menos imagem uma página tiver, maior o tempo de carregamento no computador do leitor. Se eu colocar várias imagens, o tempo pode ser uma eternidade para os leitores que possuem uma velocidade baixa de conexão. Outra coisa a ser notada é que por conta disso, o tamanho da imagem não pode ser muito grande. Portanto, eu sempre as otimizo em termos de tamanho e KB para que a experiência do leitor seja a melhor possível e assim o meu site seja bem colocado nas buscas do Google (tanto em textos quanto em imagens). (e-mail de 27 de junho de 2013).

No blog "It is a breeze", há um maior número de imagens por postagem. Além das relacionadas ao conteúdo, os recursos visuais são empregados como links, separadores de atividades e marcadores. Além de se relacionarem, essas funções também estão ligadas à função conativa das imagens, ou seja, as imagens como elemento para atrair, motivar a participação dos alunos. O fato de o público alvo ser alunos do ensino fundamental reforça tal noção uma vez que há uma maior intimidade desta faixa etária com imagens (jogos, Internet...). Além disso, o uso de recursos visuais (cartazes, realia...) já faz parte da prática dos professores de língua estrangeira há muito tempo (método audiovisual, por exemplo) e o blog acaba reproduzindo esta postura.

Grande parte das linguagens imagéticas analisadas nos dois blogs são ícones com função indicial. Tais representações visuais híbridas marcam a junção entre as duas línguas e a relação destas com o objeto dinâmico. A natureza hipoicônica das imagens facilita a aquisição da língua e diminui a possibilidade de percepções ambíguas. Embora a maioria das imagens refira-se a classes e não a objetos específicos (aspecto simbólico), o caráter referencial é determinado pela sua conexão com códigos verbais (elemento de ligação entre as duas línguas) e com o fato de revelar vestígios de objetos da realidade. Um exemplo é a foto abaixo. Além da semelhança com o objeto físico, ela conduz o leitor ao sentido/ tema do texto verbal:

Figura 1 - Tipos de água 


\section{Revista Docência e Cibercultura}

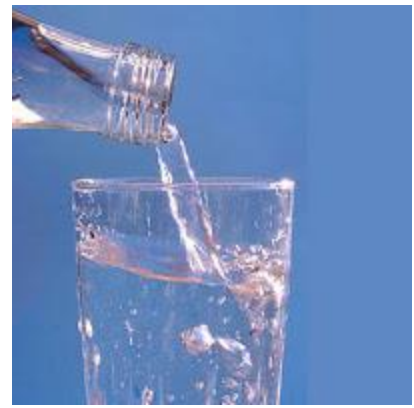

Fonte: 〈http://www.inglesnapontadalingua.com.br/2009/01/collocations-gua-doce-gua-salgada-gua.html>. Acesso em 12 ago. 2018

O desenho abaixo é outro exemplo de signos que estabelecem uma relação associativa com o tema da postagem:

Figura 2 - Profissões em inglês

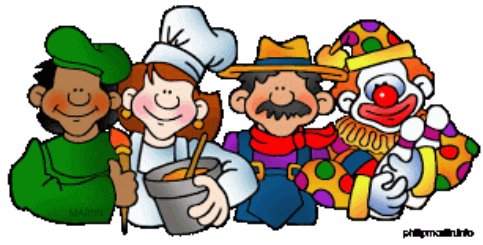

Fonte: 〈http://itisabreeze.blogspot.com.br/2013/08/occupations.html>. Acesso em 12 ago. 2018.

Apesar de ficar clara a supremacia dos signos indiciais com características hipoicônicas nos textos investigados, é precípua a análise do emprego de símbolos nas publicações estudadas. Como se sabe, para o entendimento de um símbolo é necessário o conhecimento de certos códigos convencionais. A própria língua inglesa, objeto de ensino dos blogs, é um símbolo e é o sistema deste elemento simbólico que está sendo ensinado. Não se pode esquecer também que há componentes indiciais e icônicos no símbolo, ou seja, o signo pode ser constituído por diferentes naturezas. Os signos abaixo são também exemplos de representações simbólicas universais (casamento, Jogos Olímpicos e Páscoa).

Figuras 3, 4 e 5 - Alianças / Olimpíadas / Páscoa 


\section{Revista Docência e Cibercultura}

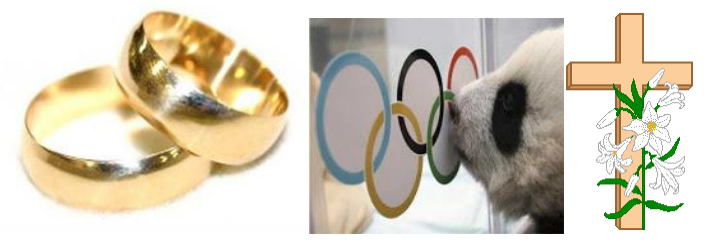

Fontes: < https://www.inglesnapontadalingua.com.br/2010/08/como-dizer-bodas-de-casamento-em-ingles.html> , <https://www.inglesnapontadalingua.com.br/2008/08/que-venham-os-jogos-olmpicos.html >e <http://itisabreeze.blogspot.com.br/2012/10/time-expressions.html >-.Acesso em 12 ago. 2018.

É claro que a interpretação de um símbolo sofre alterações de acordo com o contexto e a perspectiva de quem o examina. Em alguns casos, no entanto, o entendimento fica comprometido. Tal fato geralmente está vinculado ao caráter mais subjetivo da mensagem transmitida. As duas imagens escolhidas apresentam bonecos Playmobil. A primeira representação retrata um boneco ninja sobre a página de uma gramática de língua inglesa:

Figura 6 - Boneco Ninja

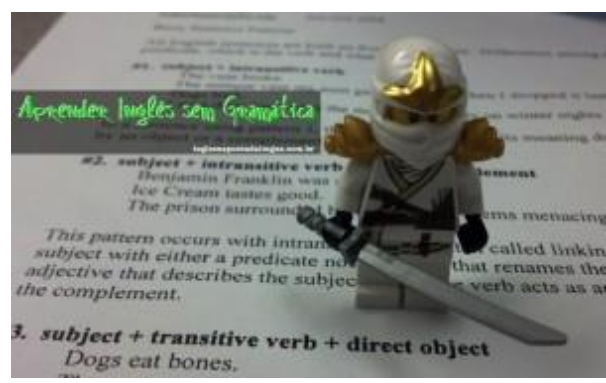

Fonte:< https://www.inglesnapontadalingua.com.br/2013/04/aprender-ingles-sem-gramatica.html> . Acesso em 26 ago.

2013.

Tendo por base apenas a fotografia e o assunto do texto verbal (“Aprender Inglês sem Gramática”) não se tem uma percepção clara da mensagem que o signo imagético comunica. O autor do blog comenta sobre seu sentido:

Eu optei por essa imagem não só por ter a página de um livro de gramática. O interessante aí é a presença de um ninja vestido de branco. Por quê?

Em várias de minhas palestras em faculdades pelo Brasil, quando eu falava sobre esse tema, os participantes mencionavam que para aprender inglês sem se prender à gramática, o estudante deveria ser um ninja. Todo ninja tem um início de treinamento (não se nasce um ninja - você treina muito para ser um). Então, na imagem tem um ninja vestido de branco que é geralmente a cor da faixa de quem inicia em artes marciais. Com essa 


\section{Revista Docência e Cibercultura}

imagem eu juntava tudo isso e só precisava escrever algo sobre ela. Que foi o que fiz! Isso tudo está implícito na imagem. No texto, eu não faço referência a absolutamente nada disso. Maluquice, não! (e-mail de 27 de junho de 2013)

O outro exemplo selecionado para exemplificar está situação apresenta o boneco de Darth Vader, personagem do filme Guerra nas Estrelas de George Lucas. O boneco encontra-se em uma sala de aula apresentando um desenho da Estrela da Morte para três soldados:

Figura 7- Darth Vader na sala de aula

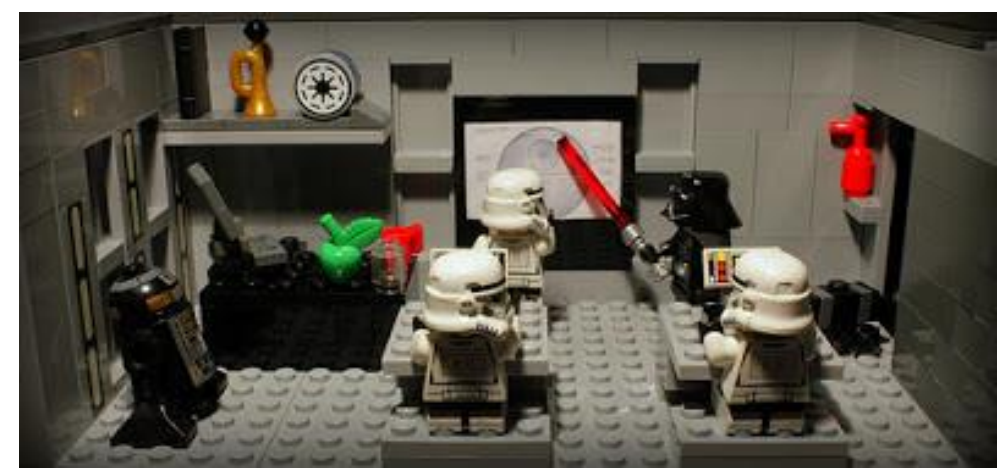

Fonte: <http://itisabreeze.blogspot.com.br/2013/05/classroom-language.html〉._Acesso em 12 ago. 2018.

A postagem em que esta fotografia está inserida lida com as expressões utilizadas em sala de aula. O ambiente da sala de aula fica claro no signo visual pela disposição das carteiras e pela presença de uma maçã, símbolo relacionado ao professor. Contudo, parte da mensagem não fica acessível. Uma vez que os personagens são militares, eles funcionam como símbolos de regulamentos, cumprimento de regras. Tal fato reflete, de uma forma exagerada, o uso do imperativo no espaço escolar (códigos, instruções...). Além disto, o destaque para a cor vermelha (símbolo de poder, de liderança e de perigo) num local marcado pelas cores cinza e preta busca representar a falta de vida da sala de aula caracterizada por atitudes autoritárias.

Como foi destacado acima, a preferência pelo uso de signos indiciais com aspectos icônicos no ensino de língua inglesa parece atestar a busca pela compreensão inequívoca da mensagem. Tal circunstância parece ocorrer nos blogs analisados.

\section{RELAÇÕES SEMÂNTICAS ENTRE LINGUAGENS}




\section{Revista Docência e Cibercultura}

Muitos autores discutem o diálogo entre imagens e contextos verbais. A imagem pode apresentar função estética, repetir informações presentes no código linguístico, adicionar dados, fazer comentários e esclarecer itens. O signo visual também pode ser interpretado com o auxílio das palavras ou por elas ser modificado. Nos blogs estudados, este aspecto semântico da relação entre os dois códigos é marcado pelo que Santaella (2012, p. 113) chama de dominância do texto escrito. Além disto, a imagem possui função redundante em relação à transmissão da mensagem uma vez que é inferior ao texto verbal e não interfere na compreensão do significado. A figura abaixo reflete tal posição visto que o sentido de todos os termos já é apresentado no texto verbal (a tradução é colocada acima da imagem e a imagem também apresenta os elementos na língua inglesa). A predominância da cor vermelha, associada a elementos maliciosos ou pecaminosos, apenas reforça o que foi visto na modalidade linguística:

Figura 8 - Os setes pecados capitais em inglês

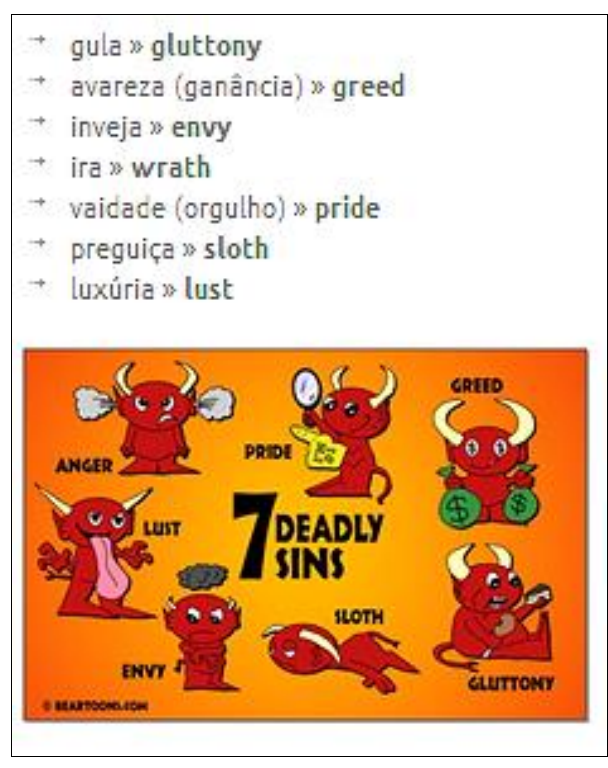

Fonte: < https://www.inglesnapontadalingua.com.br/2013/06/os-7-pecados-capitais-em-ingles.html >. Acesso em 27 ago. 2013

Em algumas publicações nos blogs, no entanto, além do conteúdo da mensagem ainda estar centrado no texto verbal, a compreensão da linguagem visual demanda uma leitura mais detalhada. O exemplo abaixo é uma amostra deste fato. Na postagem, o blogueiro apresenta textos em inglês para iniciantes. A foto reflete o objetivo da postagem ao apresentar uma criança (novato) lendo um livro. 


\section{Revista Docência e Cibercultura}

Contudo, a representatividade da imagem é limitada porque depende da modalidade linguística, ou seja, só se entende o que o retrato exprime quando é feita a decodificação verbal:

Figura 9 - Leitura para iniciantes

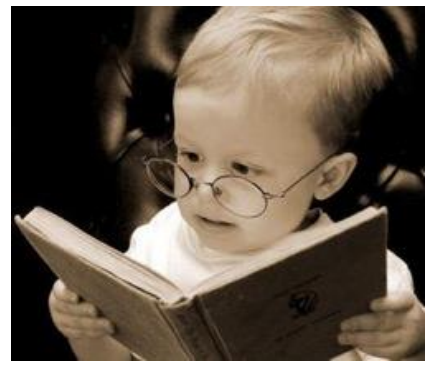

Fonte: < https://www.inglesnapontadalingua.com.br/2009/03/textos-em-ingles-para-iniciantes.html >. Acesso em 12 ago. 2018

Parece claro no estudo desenvolvido que o uso da linguagem visual ainda é visto como um recurso inferior nos blogs. Apesar de haver textos visuais que possuem uma relação de complementaridade com o texto verbal, há um predomínio de imagens com função meramente ilustrativa. A mediação entre o aprendiz e a língua inglesa se dá, na maioria dos casos, pelo uso da língua materna. Em grande parte das postagens analisadas, não há uma unidade de sentido, ou seja, a imagem pouco interfere na comunicação. Até mesmo o texto imagético que agrega informação encontra-se, em muitos casos, subordinado ao texto verbal ou possui uma representatividade limitada.

\section{NOSSAS OBSERVAÇÕES}

O uso das imagens nos dois edublogs parece refletir, em grande parte, a prática comumente observada em sala de aula pelas pesquisadoras e os comentários feitos pelos professores de línguas que participaram da pesquisa inicial. No ensino de uma língua, em ambiente físico ou virtual, a ênfase na relação entre objeto (língua) e o signo (figura) aparenta ser primordial. Nos blogs, onde a não linearidade das imagens é refletida no hipertexto, apesar da hibridização das linguagens e de seus múltiplos usos (como links, por exemplo), a preocupação com a aproximação entre a dimensão semântica e as características existenciais aparenta ser uma constante. 
É oportuno salientar também que, além da dominância do texto verbal escrito, os recursos visuais desempenham, em grande parte das postagens, um papel redundante e inferior. Quase toda a comunicação apoia-se no uso das linguagens verbais (língua inglesa e língua portuguesa). Em muitos casos, não há sequer uma relação referencial entre o texto verbal e o imagético. Com isto, reduz-se o campo de opções para uma aprendizagem significativa.

\section{CONSIDERAÇÕES FINAIS}

Em nosso estudo, é perceptível que a interpretação das representações visuais não repousa em um único olhar. Por se tratar de uma relação dinâmica e complexa, não há respostas prontas na análise dos signos visuais. O mesmo pode ser dito em relação à metodologia empregada em nosso trabalho. Assim como a imagem, o estudo de caso apresenta um recorte do objeto de estudo e, como tal, nunca é completo. Ao fazer uso desta metodologia para examinar um elemento que se caracteriza pela ambiguidade, tinha-se ciência que não seriam obtidos resultados definitivos. Na realidade, buscou-se abrir possibilidades para novas discussões e novas pesquisas.

Ao escolher analisar blogs educativos, estava-se consciente do quão longe eles ainda se encontram da realidade escolar. Os meios digitais não são soluções para a educação, mas podem minimizar algumas dificuldades. Em outras palavras, os recursos digitais podem ser usados para trabalhar conteúdos, trocar informações, construir atividades, ou seja, sem as limitações do meio físico. Blogs, wikis e redes sociais, assim, passam a ser ambientes educativos uma vez que são capazes de criar situações de aprendizagem de acordo com os objetivos e necessidades do trabalho educativo. Contudo, para que isto ocorra, não se pode pensar nestas interfaces como extensões da sala de aula.

Em relação ao uso da imagem em ambientes pedagógicos, é patente a importância dada pelos professores de língua. Contudo, apesar do reconhecimento de seu valor, tal emprego ainda está vinculado a fatores externos. As imagens e seus sentidos não são construídos, mas recebidos de forma passiva (prática do download) e através dos materiais impressos (livros didáticos). Em oposição a esta solidificação no uso dos recursos visuais, é possível, através das novas tecnologias, criar mensagens fluidas, onde imagens são alteradas e fragmentadas, onde diferentes códigos se mesclam como peças de um quebra-cabeça. Tal possibilidade permite uma participação crítica no 
processo pedagógico. Pode-se dizer, então, que a aprendizagem só ocorre quando todos os envolvidos deixam de ser receptores de mensagens e se transformam em criadores das mesmas, independente do meio ou do código usado.

A fim de obter a coexistência significativa entre as diferentes linguagens, é necessário conhecer os sistemas que as caracterizam. Do mesmo modo que é indispensável conhecer os sons, os vocábulos e as estruturas que formam a língua inglesa para poder utilizá-la de forma comunicativa, torna-se essencial o conhecimento dos elementos que constituem a cultura visual para poder empregá-la de maneira produtiva.

\section{REFERÊNCIAS}

ARAÚJO, E. V. F. Letramento em contexto digital: diferentes práticas de leitura e escrita. Apresentado no XV Congresso Nacional de Linguística e Filologia. Anais... Rio de Janeiro, 2011. Disponível em: 〈http://www.filologia.org.br/xv_cnlf/tomo_1/56.pdf>. Acesso em 12 ago. 2018.

BAUMAN, Z. Tempos líquidos. Rio de Janeiro: Jorge Zahar Ed., 2007.

BELL, D. The coming of post-industrial society: a venture in social forecasting. New York: Basic Books, 1999.

BEMEZER, J. et al. Using a Social Semiotic Approach to Multimodality: Researching Learning in Schools, Museums and Hospitals. National Centre for Research Methods. UK, March 2012,

p. 1 - $14 . \quad$ Disponível em: <http://eprints.ncrm.ac.uk/2258/4/NCRM_working_paper_0112.pdf > . Acesso em 12 de agosto de 2018.

; KRESS, G. Writing in Multimodal Texts: A Social Semiotic Account of Designs for Learning. Written Communication. Sage: April, p.166-195, 2008.

COSTA, C. Educação, imagem e mídias. $2^{\mathrm{a}}$ ed. São Paulo: Cortez, 2013.

GADOTTI, M. A escola e o professor: Paulo Freire e a paixão de ensinar. São Paulo: Publisher Brasil, $2007 . \quad$ Disponível em: <http://www.acervo.paulofreire.org:8080/jspui/bitstream/7891/2773/1/FPF_PTPF_12_026.pd f $>$. Acesso em 12 ago. 2018.

JEWITT, C. Multimodality, "reading", and "writing" for the 21st Century. Discourse: studies in the cultural politics of education, v. 26, n. 3, p. 315-331, Sept. 2005. Disponível em: $\langle$ http://culturemediaed.pressible.org/files/2011/09/jewitt_multimodality.pdf $>$. Acesso em 12 ago. 2018.

. Multimodality and literacy in school classrooms. Review of Research in Education, v. 32, Feb 1, p. 241-267, 2008. Disponível em: < http://journals.sagepub.com/doi/full/10.3102/0091732X07310586 >. Acesso em 12 ago. 2018. 
KRESS, G. R. Multimodality: a social semiotic approach to contemporary communication. London and New York: Routledge, 2010.

LIMA, D. Mensagem eletrônica pessoal. Recebida em 27 de junho de 2013.

MORAN, J. M.; MASETTO, M. T.; BEHRENS, M. A. Novas Tecnologias e Mediação Pedagógica. 13. ed. Campinas: Papirus, 2007.

NOVA, C.; ALVES, L. Estação online: a ciberescrita, as imagens e a EAD. In SILVA, M. (Org.). Educação Online. 2. ed. São Paulo: Edições Loyola, p. 107-136, 2006.

NÖTH, W. Panorama da Semiótica: de Platão a Peirce. 4. ed. São Paulo: Annablume, 2008.

PARENTE, A. (Org.). Imagem-máquina: a era das tecnologias do virtual. 3. ed. Rio de Janeiro: Ed. 34, 1999.

PEIRCE, C. S. L 463: Letter to Lady Welby. Milford, 1904. Disponível em: < http://www.unav.es/gep/Welby12.10.04.html>. Acesso em 12 ago. 2018.

. Collected Papers of Charles Sanders Peirce, Volume 1: Principles of Philosophy. 1931. Disponível em: <http://www.textlog.de/peirce_principles.html >. Acesso em 21 de abril de 2017.

RAMAL, A. C. Educação com tecnologias digitais: uma revolução epistemológica em mãos do desenho instrucional. In: SILVA, M. (Org.). Educação Online. 2. ed. São Paulo: Edições Loyola, 2006, p. 185-200.

ROJO, R. Pedagogia dos multiletramentos: diversidade cultural e de linguagens na escola. In: ROJO, R.; MOURA, E. (Org.). Multiletramentos na escola. São Paulo: Parábola Editorial, 2012, p. 11-31.

SANTAELlA, L. O que é semiótica. Coleção Primeiros Passos 103. São Paulo: Brasiliense, 1983. . Matrizes da linguagem e pensamento: sonora, visual, verbal: aplicações na hipermídia. 3. ed. São Paulo: Iluminuras, FAPESP, 2005.

. Leitura de Imagens. São Paulo: Editora Melhoramentos, 2012. (Coleção Como eu ensino). ; NÖTH, W. Imagem: cognição, semiótica, mídia. 6. ed. São Paulo: Illuminuras, 2012.

SANTOS, R. Pesquisa colaborativa e redes sociais na escola básica: desafios e potenciais dos blogs. Revista Magistro, v. 2, n. 2, p. 42-56, 2010. Disponível em: <http://publicacoes.unigranrio.edu.br/index.php/magistro/article/view/1181/698> Acesso em 12 ago. 2018.

SILVA, M. (Org.). Educação online. 2. ed. São Paulo: Edições Loyola, 2006.

THE NEW LONDON GROUP. A pedagogy of multiliteracies: designing social futures. Harvard Educational Review, v. 66, n. 1, p. 60-92, 1996 Disponível em: <http://vassarliteracy.pbworks.com/f/Pedagogy+of+Multiliteracies_New+London+Group.pdf $\geq$. Acesso em 12 ago. 2018.

UNSWORTH, L. Teaching multiliteracies across the curriculum: changing contexts of text and image in classroom practice. Buckingham: Open University, 2001.

VYGOTSKY, L. S. Formação social da mente. 4. ed. São Paulo: Martins Fontes, 1991.

YIN, R. K. Case study research: design and methods. 4. ed. Applied Social Research Methods, v.5, 2009. 